\title{
Mating effort function of the spermatophore in the bushcricket Poecilimon veluchianus (Orthoptera, Phaneropteridae): support from a comparison of the mating behaviour of two subspecies
}

\author{
KLAUS-GERHARD HELLER AND KLAUS REINHOLD \\ Department of Zoology II, University of Erlangen-Nürnberg, Staudtstr. 5, D-91058 \\ Erlangen, Germany
}

Received 30 March 1993, accepled for publication 20 January 1994

\begin{abstract}
To analyse spermatophore function, various aspects of the mating behaviour (e.g. spermatophore mass, duration of sperm transfer, mating frequency) were compared in two subspecies of the bushcricket $P$. veluchianus. Body mass was significantly different in both subspecies and had a strong effect on spermatophore mass, resulting in a large difference in absolute and relative (percentage of male body mass) spermatophore mass in both subspecies. After copulation the small $P$. v. minor spermatophores were consumed much faster by the female than the larger ones of $P$. v. veluchianus. The time necessary for sperm transfer from the spermatophore to the female spermatheca was much shorter in the subspecies with small spermatophores than in that with large spermatophores, and in both subspecies similar to the time required to consume the spermatophores. Mating frequency varied also between the subspecies and was much higher in $P$. v. minor than in P. v. veluchianus. Differences in body mass between the two subspecies therefore resulted in changes in several aspects of mating behaviour. However, despite large differences in the mass of the spermatophore, its main function seems to be to ensure sperm transfer. This can be concluded from the similarity between the duration of sperm transfer and the time period necessary for spermatophore consumption in each of the subspecies. The spermatophore is thus considered to be male mating effort.
\end{abstract}

ADDITIONAL KEY WORDS:-Sperm transfer - acoustic communication - mating effort.

\section{CONTENTS}

Introduction

Material and methods.

Results

Calling activity

Body mass and population density.

Size of spermatophore

Duration of sperm transfer and of spermatophore consumption .

Time of mating and mating frequency.

Discussion

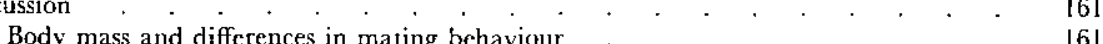

Spermatophore function . . . . . . . . . . . . . . . . .

Acknowledgements

References

\section{INTRODLCIION}

Courtship feeding, i.e. the male providing the female with food during or after mating, occurs in a variety of insects (Thornhill \& Alcock, 1983). One of the 
most intensively studied examples is the bushcricket spermatophore (for literature, see Wedell, 1993; Simmons \& Gwynne, 1993). During mating, male tettigoniids transfer a large gelatinous mass, the spermatophylax, attached to the sperm-containing ampulla. Immediately after mating, the female consumes first the spermatophylax and thereafter starts to eat the ampulla. During the consumption of the spermatophylax, the sperm is transferred from the ampulla into the female spermatheca. The size of the spermatophylax varies considerably between species ranging from tiny up to more than $30 \%$ of male body mass (Busnel \& Dumortier, 1955; Gwynne, 1990). As far as the function of the spermatophore and the spermatophylax respectively are concerned, speciesspecific differences also seem to exist. The large spermatophore of Requena verticalis males (up to $20 \%$ of male body weight; Gwynne, 1986) has been shown to represent paternal investment, i.e. by providing the females with the spermatophore the male is able to increase the number and survival of its offspring (Gwynne, 1986, 1988). In this species sperm transfer is completed noticeably faster than spermatophylax consumption by the female. In Decticus verrucivorus, however, the small spermatophore (about $9 \%$ of male body mass) only increases male fertilization success, and not the survival of its offspring or egg number (Wedell \& Arak, 1989), and has therefore been classified as mating effort. The duration of sperm transfer and of spermatophore consumption by the female seem to be in the same range and males with larger spermatophores are superior in sperm competition (Wedell, 1991).

Going from these two examples, spermatophore size could be considered a predictor of spermatophore function (e.g. Will \& Sakaluk, 1994). The situation, however, is obviously more complicated. In the bushcricket $P$. veluchianus (veluchianus) the main function of the large spermatophore, about $25 \%$ of male body mass, seems to be ejaculate protection during insemination. In about $20 \%$ of matings the spermatophylax is too small to ensure successful sperm transfer (Reinhold \& Heller, 1993). In other bushcricket species, males have been shown to adjust spematophore size according to age (Requena verticalis; Simmons et al., 1993 ) or the mating status (virgin or non-virgin) (Decticus verrucivorus; Wedell, 1992) of their mates. In both species the males produce smaller spermatophores when lower reproductive success can be expected. This behaviour may enable the males to remate faster than after the production of large spermatophores. In general, however, the size of the spermatophore seems to be of species-specific character, or is characteristic for species groups or subfamilies (Gwynne, 1990), indicating the same function in all related species and low potential for evolutionary change. There are, however, exceptions to this pattern with different species of the same genus producing differently shaped (Leptophyes Gerhardt, 1913, 1914) or sized (Poecilimon Heller \& Helversen, 1991) spermatophores.

The data presented here show that even within the same species different spermatophore sizes can be found. Two subspecies of Poecilimon veluchianus differ genetically in body size (Reinhold, 1994). The ultimate reason for this difference is probably associated with the ecology of the subspecies, the smaller one becoming adult earlier and occurring in the lowlands, the larger one typically found in mountainous regions and maturing later in the season (Heller \& Reinhold, 1993). According to our results, both subspecies differ in absolute and relative (in percentage of male body mass) spematophore mass, due largely to 
different body size. Despite these and other differences in mating behaviour, e.g. in malc acoustic behaviour and mating frequency (see below), the main function of the spermatophylax in both subspecies is to ensure sperm transfer to the female.

\section{MATERIAL AND MEIHODS}

Poecilimon veluchianus is a medium sized (see Table l) bushcricket endemic in Central Greece (Willemse \& Heller, 1992). P. veluchianus veluchianus Ramme, 1930 , occurs in the mountains of the central and western part of Central Greece, while P. veluchianus minor Heller \& Reinhold, 1993, is restricted to the eastern lowland areas (Heller \& Reinhold, 1993).

All observations and experiments described below were carried out $3 \mathrm{~km}$ north of the village of Vitoli $\left(22^{\circ} 0 \mathrm{l}^{\prime} \mathrm{E}, 38^{\circ} 58^{\prime} \mathrm{N} ; P\right.$. v. veluchianus $)$ and below the village of Tsouka $\left(22^{\circ} 05^{\prime} \mathrm{E}, 38^{\circ} 57^{\prime} \mathrm{N} ; P\right.$. v. minor $)$, both near the village of Makrakomi, Nomos Fthiotis, and both situated about $330 \mathrm{~m}$ above sea level. The distance between the two localities is about $6.5 \mathrm{~km}$.

In Vitoli the study area, of about $540 \mathrm{~m}^{2}$, was situated at the bottom of a small valley, bordered on one side by a creek and on the other side by dense forest or areas without vegetation. In spring 1987, 393 animals (173 $\delta \delta, 220$ of $)$ were

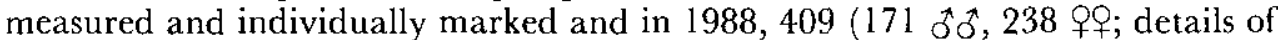
marking see Heller \& Helversen, 1990).

In Tsouka the animals live on a gentle slope, exposed to the North (study area $310 \mathrm{~m}^{2}$ in $1987,185 \mathrm{~m}^{2}$ in 1988 ). On most days the temperature was higher than in Vitoli. In spring 1987, 302 animals (149 $\delta \delta^{\circ}, 153$ 우) were measured and marked and in 1988, 580 (258 कै कै, 322 우). Population density was determined from capture-recapture data (for calculation see Heller \& Helversen, 1991).

The acoustic behaviour of the animals, active mainly at night, was monitored over a number of days with a QMG-Mini-batdetector. In addition, calling activity of the males was recorded continuously in the habitat for a period of $24 \mathrm{~h}$ (twice in each population) using an UHER 4400 tape recorder operating at $2.4 \mathrm{~cm} / \mathrm{s}$. Tapes were evaluated via a self-constructed computer-interface or by hand, using a Zirelco Datapad ZE 661 computer for registration (Heller \& Helversen, 1993).

The percentage of copulating females per day was determined by two surveys each night in Vitoli, comparing the number of females with and without spermatophores ( $n=41$ days; for calculations see Heller \& Helversen, 1991; days with rain were excluded from both populations). In Tsouka, where the females consumed the spermatophore much faster (see Results), the data obtained by the same method ( $n=13$ days) were only used for an estimate of the lower limit of mating frequency. They were compared with an almost nearly continuous observation of mating activity on 29/30 May 1988 (nine surveys, each lasting about $1.25 \mathrm{~h}$; for exact times of day see Fig. 5). Using the data from this day, we estimated the mating frequency on other days, assuming that the number of females observed with spematophores during the first survey represents $31 \%$ of all females mating during the respective day and during the second survey $27 \%$ (see Fig. 5; mean of the two estimates used in Fig. 4).

Data from this same survey were used to make an estimate for the time period taken by a female to consume the spermatophore. Here only data were used 
from those females which were observed initially without, then one to several times with and again without spermatophore. For the calculation of feeding duration, half of the period between final observation of the female without spematophore and the first observation with spermatophore was added to the time the female was observed with spermatophore, and half of the period between the last observation with spermatophore and the first without.

Spermatophore mass was measured in males that were at least 8 days old and had not copulated for at least three days. A male was placed together with a virgin female and both weighed immediately before the experiment. Usually the animals copulated within one hour, and both were weighed immediately after mating (the mean used as spermatophore weight (ampulla plus spermatophylax)). If the difference between loss and gain of mass in males and females exceeded $20 \%$, the data were discarded. The weights of $P$. v. veluchianus were taken from progeny of animals from Vitoli bred in the laboratory. For both populations, the mass of accessory glands was determined by the dissection of field collected animals, at least 7 days after capture.

The time course of sperm transfer from the spermatophore to the female spermatheca was measured in $P$. v. minor in the same way as described for P. v. veluchianus (Reinhold \& Heller, 1993).

\section{RESULTS}

\section{Calling activity}

The structure of the calling song, consisting of isolated syllables, was very similar in both subspecies. However, while the $P$. v. veluchianus males called almost exclusively at night (Fig. 1; see also Heller \& Helversen, 1993), the $P$. v. minor males were active during a longer period of the day. Singing started

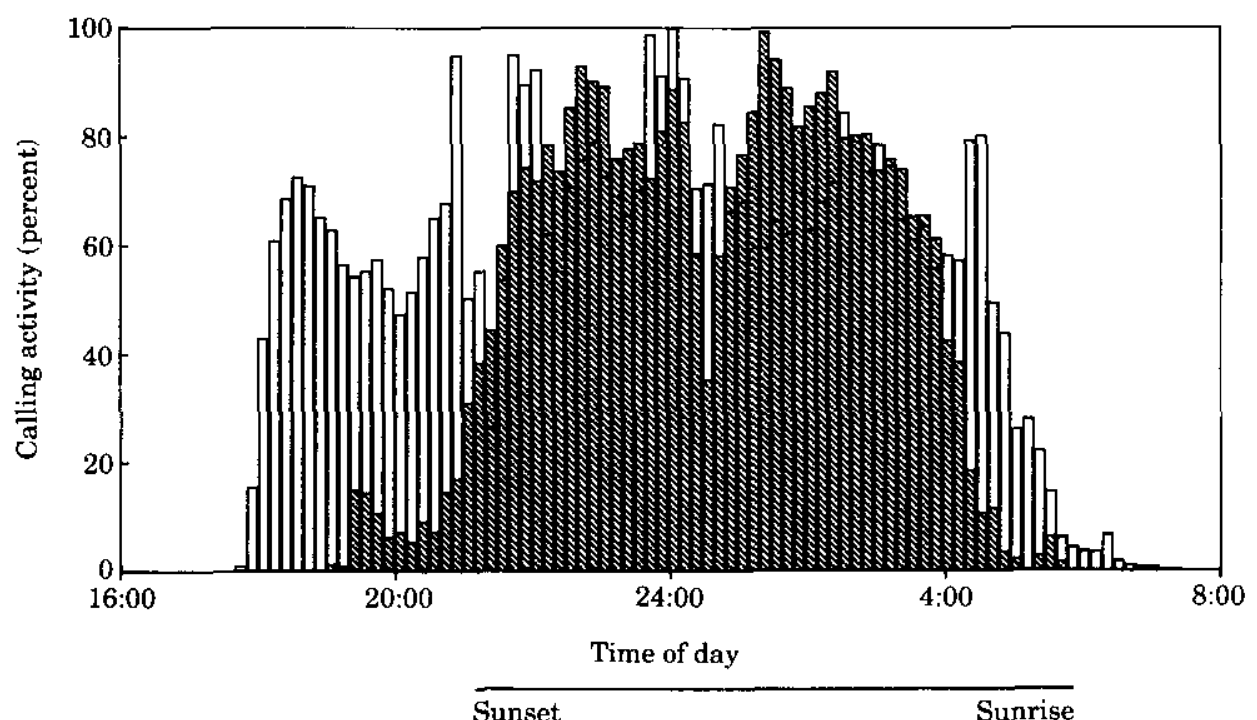

Figure 1 . Diel calling activity pattern, recorded in the field (in per cent of maximum activity) at $6 / 7$ June 1988 in $P$. v. veluchiants $\mathbb{N}$ and $7 / 8$ June 1988 in $P$. v. minor $\square$. 
TABLE 1. Comparison of body mass (Mean \pm SD; sample size in parentheses; 3-factor-ANOVA: subspecies $F=978.8$, $P<0.001 ; \quad$ sex $F=199.4, \quad P<0.001 ;$ year $F=62.8$, $P<0.001 ;$ interactions not significant)

\begin{tabular}{|c|c|c|}
\hline & \multicolumn{2}{|c|}{ Body mass $(\mathrm{g})$} \\
\hline & 88 & Q⿻日土 \\
\hline \multicolumn{3}{|l|}{$P . v$. veluchianus } \\
\hline Vitoli lo June 1987 & $0.62 \pm 0.11(76)$ & $0.71 \pm 0.15(102)$ \\
\hline 5 June 1988 & $0.66 \pm 0.11(99)$ & $0.77 \pm 0.13(104)$ \\
\hline \multicolumn{3}{|l|}{ P.v. minor } \\
\hline Tsouka 2 June 1987 & $0.33 \pm 0.06(67)$ & $0.45 \pm 0.08$ \\
\hline 29 May 1988 & $0.40 \pm 0.06$ & $0.54 \pm 0.07(91)$ \\
\hline
\end{tabular}

between 6 and 7 p.m. (Fig. 1), but on a few days high calling activity was registered as early as 4 p.m., which sometimes continued until 8 a.m. This was never the case with P. v. veluchianus. At both localities, $P$. veluchianus was the acoustically dominating bushcricket species with only few individuals of other species calling.

\section{Body mass and population density}

Animals from Tsouka ( $P . v$. minor) were lighter than those from Vitoli which belong to the nominate subspecies (Table 1). In both populations females were heavier than males, and in 1988 all means were higher than in 1987 which could result from a different age: in 1988 the animals were probably older than in 1987 at time of weighing (compare dates with fig. 4 in Heller \& Reinhold, 1993).

The estimates for population density obtained in Tsouka (P.v. minor) were distinctly higher than in Vitoli ( $P$. v. veluchianus). While the results in Vitoli were very similar on both occasions (1987: 0.57 animals per $\mathrm{m}^{2}, 1988: 0.60$ ), large differences were observed in Tsouka (1987: 0.86 animals per $\mathrm{m}^{2}, 1988: 2.12$ ), possibly partly due to the fact that in this case different areas, separated by a distance of $30 \mathrm{~m}$, were examined each year.

\section{Size of spermatophore}

The mass of spermatophores transferred during copulation differed between subspecies (mean $\pm \mathrm{SD} ; \quad P . v$. minor: $74 \mathrm{mg} \pm 14 ; \quad n=271 ; \quad P$. v. veluchianus: $162 \mathrm{mg} \pm 43 ; n=61$ ) and was significantly correlated to male body mass (Fig. 2). The analysis of covariance showed that both populations did not differ significantly (covariate male body mass $F=331.1, P<0.001$; effect of subspecies $F=0.821, P=0.38$ ). We neglect the heterogeneity among the slopes obtained in each population $(F=5.17$, df $=1,84, P=0.03)$, because this heterogeneity was not found in analysing the mass of accessory glands (see below), a very similar measurement which is often used to examine spermatophore size (e.g. Simmons \& Bailey, 1990). If both subspecies were treated separately, in every case there was a significant positive correlation between male body mass and spermatophore mass. The relative spermatophore mass as percentage of male body weight was significantly different between both 


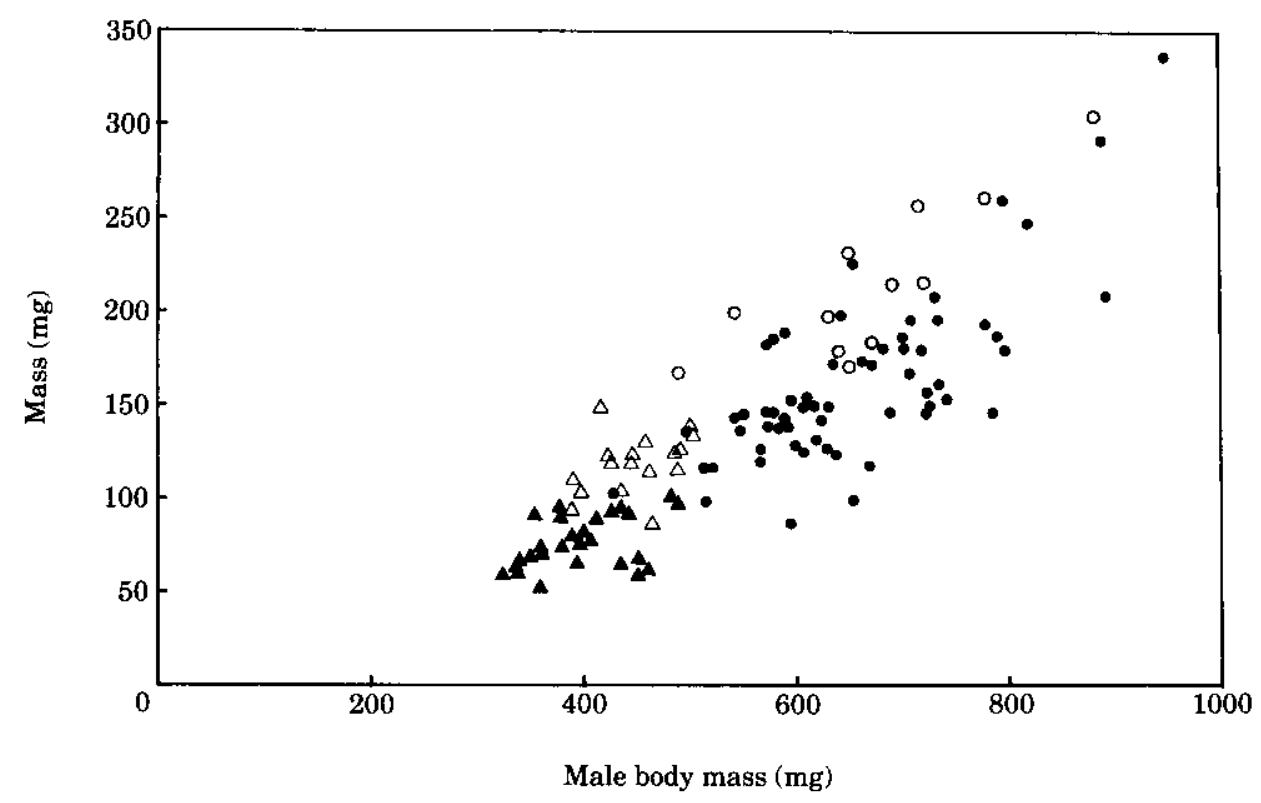

Figure 2. Mass of spermatophores (filled symbols) and of accessory glands (open symbols) in relation to male body mass (ANCOVA statistics see text). $\triangle \Delta$ P. v. minor. O P. v. veluchianus.

groups (mean $\pm \mathrm{SE} ;$ P. v.v.: 24.9\% $\pm 0.5 ;$ P. v. m.: $19.1 \% \pm 0.6$; ANCOVA: covariate male body mass: $F=37.2, P<0.001$; effect of subspecies $F=7.6$, $P<0.01$; slopes of regression lines were not significantly different $F=3.56$; $\mathrm{df}=1,84, P=0.06$ ).

The results obtained by measuring the accessory glands, which are used for spermatophore production, were very similar. Apart from the very distinctive effect of body mass, slightly significant differences between the two subspecies could be seen (ANCOVA - covariate male body mass: $F=207.2, P<0.001$; effect of subspecies $F=4.4, P=0.05$; slopes of regression lines were not significantly different $F=0.02 ; P=0.90)$.

Altogether, the results demonstrated a clear positive correlation between male body mass and absolute mass of the spermatophore. The two subspecies, however, differed in the relative spermatophore mass, being distinctly smaller in $P$. v. minor than in P. v. veluchianus.

\section{Duration of sperm transfer and of spermatophore consumption}

The duration of sperm transfer was distinctly different in both subspecies. Sperm transfer was measured by comparing the number of sperm already found in the female spermatheca and the number of sperm still left in the ampulla (the sperm-containing portion of the spermatophore) at various times after mating.

Three hours after mating more than $80 \%$ of sperm of $P$. v. minor, the subspecies with the smaller spermatophores, was transferred to the female (Fig. 3). In P. v. veluchianus, however, it took more than $12 \mathrm{~h}$ before this value was registered (2-factor ANOVA for the critical time period of 2 until $7.5 \mathrm{~h}$ after 


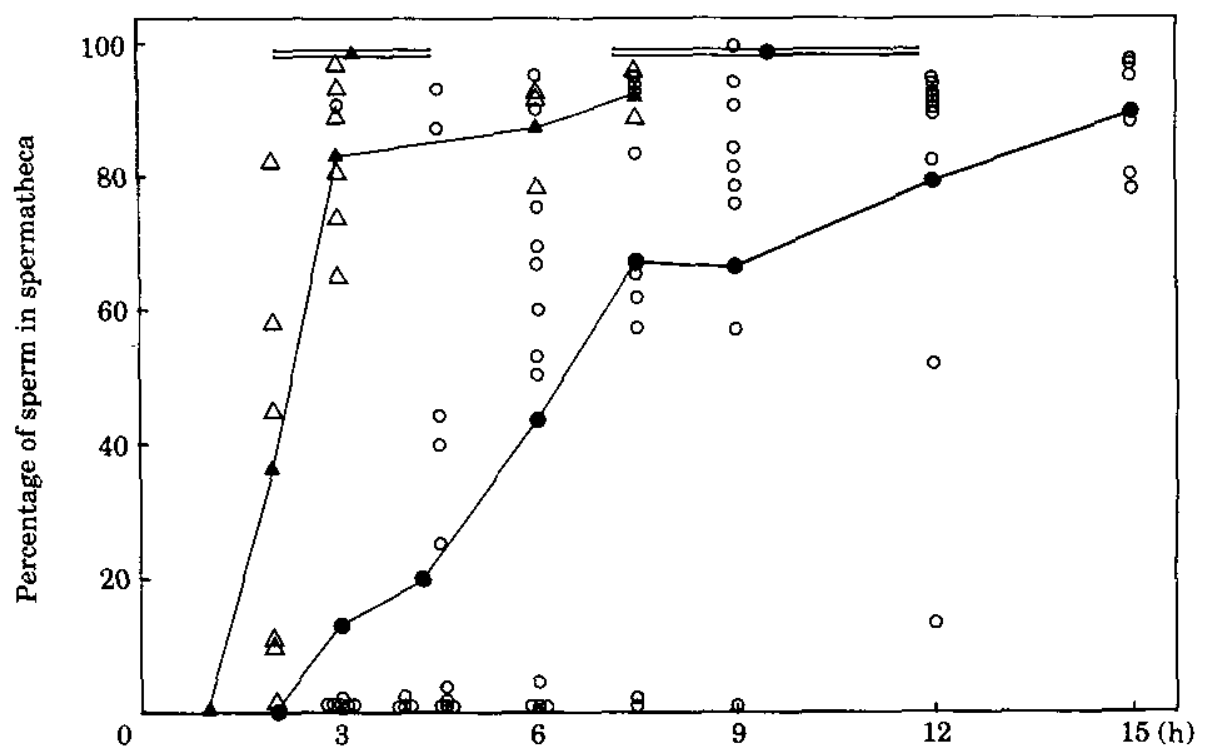

Time after copulation ( $\cong$ female feeding time)

Figure 3. Sperm transfer from the spermatophore to the spermatheca as function of time (open symbols data points, closed symbols means; $n=5$ for $1 \mathrm{~h}$ in $P$. v. minor $\Delta \mathbf{\Delta} ; n=3$ for $2 \mathrm{~h}$ in $P . v$ veluchianus $\mathrm{O}$ ). The horizontal double lines indicate spermatophore consumption duration (mean $\pm \mathrm{SD}$ ) for the two subspecies (data for P. v. veluchianus from Reinhold \& Heller, 1993).

copulation: subspecies $F=21.2, P<0.001$; time $F=8.8, P<0.01$; interaction between subspecies and time $F=0.9, P=0.44$ ).

The time period necessary for consumption of the spermatophore by the female was similar to the time necessary for complete sperm transfer in both subspecies (Fig. 3). P. v. minor females completed feeding within $3.3 \mathrm{~h} \pm 1.2$ (mean $\pm \mathrm{SD} ; n=23$ ), whereas $P$. v. veluchianus took $9.5 \mathrm{~h} \pm 2.3 ; n=24 ; \mathrm{t}=11.4$; $P<0.001$; data for P. v. veluchianus from Reinhold \& Heller, 1993).

\section{Time of mating and mating frequency}

Mating activity corresponded well to the calling activity of the males. $P$. v. veluchianus started after 9 p.m. and finished before 5 a.m. (compare Fig. 1 for calling activity), whereas $P$. v. minor started much earlier, at about 6 p.m., reaching its peak a little later (Fig. 5, compare Fig. 1 for calling activity).

In both subspecies mating frequency was calculated as a percentage of females mating per day. Due to the long time period necessary for spermatophore consumption this percentage could be estimated quite accurately in $P . v$. veluchianus (Heller \& Helversen, 1991): 18.9\% \pm 9.3 (mean $\pm \mathrm{SD}$ ) of all females observed during one night had mated (Fig. 4). In P. v. minor during one night (29/30.5.1988), when nine surveys were made at intervals of about $2 \mathrm{~h}, 132$ different females were observed; 67 were found with spermatophore, resulting in an estimate of $51 \%$ mated females. This value, however, represents a lower limit for mating frequency, since some females which had actually mated were probably only found without spermatophore because during each survey only 


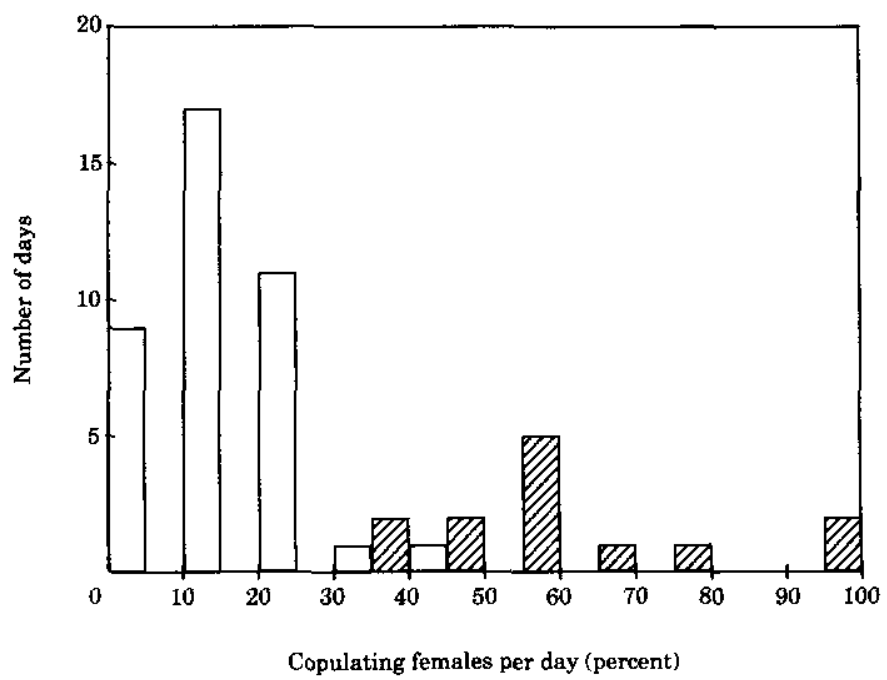

Figure 4. Frequency distribution of fernale mating frequency per day in $P$. v. veluchianus $\square(n=41)$ in 1987 and 1988 and of estimated female mating frequency (see Methods) in $P$. v. minor $(n=14)$ in 1988 (two estimates of $104 \%$ and $118 \%$ are shown at $100 \%$ ).

$42-72 \%$ of all females were observed. An estimate of $56 \%$ was obtained, when only females were considered, which were observed at least three times. During this night one female was found to have mated twice (observed with, without and again with spermatophore). The percentages of females found with spermatophores on other days $(n=13$; Fig. 5$)$, which were in the same range or even higher than on 29/30 May 1988 during the respective periods, indicated

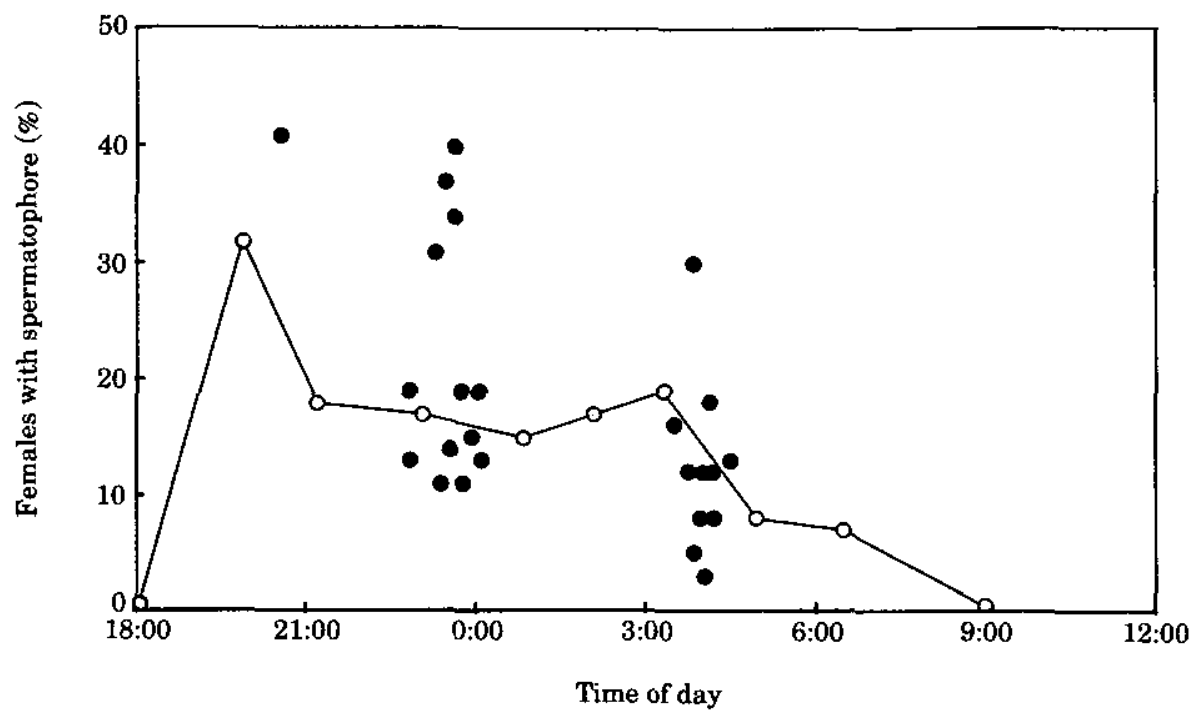

Figure 5. Female mating frequency in $P . v$. minor as percentage of females found with spermatophore (29/30 May 1988: $(n(100 \%)=55-92$ females per point, $-\mathrm{O}-$; other days $(n=13$ nights): $n(100 \%)=38-151$ females per point; mostly two observation periods per night between 22 May and 10 June 1988 . 
that the mating frequency of this population was always very high, with more than $50 \%$ of all females copulating on most days (Fig. 4). Even the sum of the percentages of females found with spermatophore during the early and late survey (mean $33 \% ; n=11$ ) was significantly higher than the mean value for $P$. v. veluchianus $(\mathrm{t}=4.1 ; P<0.001)$.

\section{DISCUSSION}

\section{Body mass and differences in mating behaviour}

According to the relationship between male body mass and spermatophore mass shown in Fig. 2, body mass can predict spermatophore mass well. Differences between both populations seem to be less important. Contrary to the bushcricket Requena verticalis (Gwynne et al., 1984), but similar to observations of a zaprochiline bushcricket (Simmons \& Bailey, 1990), large $P$. veluchianus males produce proportionally larger spermatophores than small males. Thus not only absolute, but also relative (in percentage of male body weight) spermatophore masses were significantly different in both subspecies. Relative testis size, however, was very similar in both subspecies (Reinhold, 1994).

The size of the spermatophore may affect mating frequency, which was shown to be distinctly different between the subspecies. On the one hand, a male is probably able to remate faster after the production of a small spermatophore than of a large one, as demonstrated in the comparison of the bushcrickets $P$. veluchianus (veluchianus) and $P$. affinis (Heller \& Helversen, 1991). P. v. minor males from Tsouka may be similar to $P$. affinis and frequently be able to mate every day, whereas only $33 \%$ of the $P . v$. veluchianus males remated during the day after mating (Heller \& Helversen, 1991). On the other hand, females may also mate more often, if they only receive small spermatophores: in Tsouka the female mating interval most often observed was one day (unpublished data) which is similar to the situation in P. affinis (Heller \& Helversen, 1991). In Vitoli, however, mating obviously reduced the remating probability for the next day, probably at least partly due to the larger spermatophore mass in $P$. v. veluchianus when compared to $P$. v. minor and $P$. affinis (Heller \& Helversen, 1991).

The mating frequency in Tsouka ( $P . v$. minor) may also be increased as an effect of high population density. In $P . v$. veluchianus, the number of matings in individual females correlated positively with local population density (Heller \& Helversen, 1991). In 1988, when mating frequency in Tsouka was registered, density was more than three times higher than in $P . v$. veluchianus.

Acoustic behaviour indicated increased inter-male competition in $P$. v. minor when compared to $P$. v. veluchianus. In Tsouka the animals started to call early in the evening, when probably more predators (see Heller \& Helversen, 1990) were active than during the night. Obviously, however, some factors other than intermale-competition may also favour early activity, since many females also mated at that time, behaviour not to be expected if only risks are increased. The difference in the calling behaviour between both subspecies is also consistent with the argument that individual matings are less costly for $P$. $v$. minor males due to their smaller spermatophores so that they take more risks in locating mates by calling for a longer period of time and into the daylight hours. 


\section{Spermatophore function}

The smaller spermatophores of $P . v$. minor were more quickly consumed by the females than the larger of $P$. v. veluchianus (Fig. 3). Sperm transfer time, being much shorter in $P . v$. minor than in $P . v$. veluchianus obviously corresponds to the different spermatophore mass and feeding duration. In both subspecies some spermatophores may be consumed before transferring much sperm to the females. Even in P.v. veluchianus, where female consumption time could be argued to be greater than time of insemination, about $19 \%$ of all spermatophores are probably consumed before transfer of sperm (Reinhold \& Heller, 1993). This indicates that the size of the spermatophore (respectively of the spermatophylax) is maintained by selection for successful sperm transfer and not for paternal investment. In $P$. v. veluchianus, spermatophylax consumption increases dry mass of larvae hatching from eggs and thus possibly larval fitness (Reinhold \& Heller, 1993). However, due to a strong second male advantage in sperm competition (Achmann et al., 1992) and the high female mating frequency it is unlikely that the male producing the spermatophore is fathering the profiting offspring. The same mating effort function was also described for the spermatophore of the bushcricket Deticus verrucivorus (Wedell \& Arak, 1989; Wedell, 1991). In Requena verticalis, the bushcricket with a documented paternal investment function of the spermatophylax (Gwynne, 1988), sperm transfer is much faster than the time taken by the female to consume the spermatophylax (Gwynne et al., 1984; Gwynne, 1986).

Without a paternal investment function, large spermatophores, which are probably much more costly to produce, should have distinct advantages in intermale (e.g. sperm) competition when compared to small ones, since otherwise the $P$. v. veluchianus males should also deliver only small spermatophores. One advantage of a large spermatophore over a small could be that they reduce female remating probability on the day after mating (see above). This argument, however, suffers from the point that sperm transfer of the large spermatophores is not completed within the feeding of the females, which might be expected if spermatophore size only evolved in order to reduce female remating probability. Thus, other or at least additional factors must be responsible for the large and slow transferring $P$. v. veluchianus spermatophores. One important point might be that large spermatophores are superior in sperm competition. The $P$. v. veluchianus male ampullae are larger and contain slightly, but significantly more, sperm than in P. v. minor (Reinhold, 1994). Thus more time may be necessary for sperm transfer than with smaller spermatophores. Furthermore, sperm transfer mechanisms in slowly transferring spermatophores could differ from those in fast transferring and small spermatophores. $P$. v. veluchianus males with their large spermatophores were shown to have a $90 \%$ second male advantage at fertilization (Achmann et al., 1992). There are no data on $P$.v. minor, but in order to understand the differences in mating behaviour, it would be important to see if the subspecies differ in their sperm competitive ability.

\section{ACKNOWLEDGEMENTS}

We thank M. Volleth and R. Achmann for their help with the evaluation of the activity data and all others who helped with collecting the field data. For 
discussion and comments on the manuscript our thanks go to R. Achmann, R. Butlin, D. Gwynne, O. and D. v. Helversen, M. Ritchie and one anonymous referee. $M$. Barkei assisted in the English text.

\section{REFERENCES}

Achmann R, Heller K-G, Epplen J. 1992. Last male sperm precedence in Poecilimon veluchianus (Orthoptcra: 'lettigonioidea) demonstrated by DNA-fingerprinting. Molecular Ecology 1: 47-54.

Busnel R-G, Dumortier B. 1955. Etude du cycle genital du male d'Ephippiger et son rapport avec le comportement acoustique. Bulletin de la Societe Zoologique de France 80: 23-26.

Gerhardt U. 1913. Copulation und Spermatophoren von Grylliden und Locustiden I. Zoologische Fahrbicher 35: 415-532.

Gerhardt U. 1914. Copulation und Spermatophoren von Grylliden und Locustiden II. Zoologische Jahrbücher 37: $1-64$.

Gwynne DT. 1986. Courtship feeding in katydids (Orthoptera: Tettigoniidae): investment in offspring or in obtaining fertilizations? The American Naturalist 128: 342-352.

Gwynne DT. 1988. Courtship feeding in katydids benefits the mating males's offspring. Behavioral Ecology and Sociobiology 23: 373-377.

Gwynne DT. 1990. The katydid spermatophore: evolution of a parental investment. In: Bailey WJ, Rentz DCF, eds. The Tettigoniidae. Biology, systematics and evolution. Bathurst: Crawford House Press, 27-40.

Gwynne DT, Bowen BJ, Codd CG. 1984. The function of the katydid spermatophore and its role in fecundity and insemination (Orthoptera: Tettigoniidae). Australian Journal of Zoology 32: 15-22.

Heller K-G, Helversen $D$ von. 1991. Operational sex ratio and individual mating frequencies in two bushcricket species (Orthoptera, Tettigonioidea, Poecilimon). Ethology 89: 211-228.

Heller K-G, Helversen $D$ von. 1993. Calling behaviour in bushcrickets with different communication systems (Orthoptera, Tettigonioidea, Poecilimon). Journal of Insect Behavior 6: 361-377.

Heller K-G, Helversen $O$ von. 1990. Survival of a phaneropterid bush-cricket studied by a new marking technique (Orthoptera: Phaneropteridae). Entomologia Generalis 15: 203-208.

Heller K-G, Reinhold K. 1993. A new subspecies of Poecilimon veluchianus from Greece. Articulata 8: 23-29.

Reinhold K. 1994. Inheritance of body and testes size in the bushericket Poecilimon veluchianus (Orthoptcra: Phaneropteridae) examined by subspecies hybrids. Biological fournal of the Linnean Society 52: 305-316.

Reinhold K, Heller K-G. 1993. The ultimate function of nuptial feeding in the bushcricket Poecilimon veluchionus (Orthoptera: Tettigoniidae: Phaneropterinae). Behavioral Ecology and Sociobiology 32: 55-60.

Simmons LW, Bailey WJ. 1990. Resource influenced sex roles of zaprochiline tettigoniids (Orthoptera: 'Tettigoniidac). Evolution 44: 1853-1868.

Simmons LW, Gwynne DT. 1993. Reproductive investment in bushcrickets: the allocation of male and femalc nutrients to offspring. Proceedings of the Royal Sociely of London, $B$ 252: 1-5.

Simmons LW, Graig M, Llorens T, Schinzig M, Hosken D. 1993. Bushcricket spermatophores vary in accord with sperm competition and parenteral investment theory. Proceedings of the Royal Society of London, $B$ 251: $183-186$.

Thornhill R, Alcock J. 1983. The evolution of insect mating systems. Cambridge: Harvard University Press.

Wedell N. 1991. Sperm competition selects for nuptial feeding in a bushcricket. Evolution 45: 1975-1978.

Wedell N. 1992. Protandry and mate assessment in the wartbiter Decticus verrucivorus (Orthoptera: Tettigoniidae). Behavioral Ecology and Sociobiology 31: 301-308.

Wedell N. 1993. Mating effort or paternal investment? Incorporation rate and cost of male donations in the wartbiter. Behavioral Ecology and Sociobiology 32: 239-246.

Wedell N, Arak A. 1989. The wartbiter spermatophore and its effect on female reproductive output (Orthoptera: Tettigoniidae, Decticus verrucivorus). Behavioral Ecology and Sociobiology 24: 117-125.

Will MW, Sakaluk SK. 1994. Courtship feeding in decorated crickets: is the spermatophylax a sham? Animal Behaviour (in press).

Willemse F, Heller K-G. 1992. New systematic and faunistic data on Greek species of Poecilimon Fischer, 1853 (Orthoptera: Phaneropterinae). Tijdschrift voor Entomologie 135: 299-315. 